\title{
Screening for Peripheral Arterial Disease: An Update
}

\author{
Roever $L^{1 *}$ and Peo Reis ${ }^{2}$
}

${ }^{1}$ Department of Clinical Research, Federal University of Uberlandia, MG, Brazil

${ }^{2}$ Department of Specialized and General Surgery, Federal University of Fluminense, Niteroi, Rio de Janeiro, Brazil

*Corresponding author: Roever L, Department of Clinical Research, Federal University of Uberlandia, Brazil, Tel: +553488039878; E-mail: leonardoroever@hotmail.com

Rec date: Mar 17, 2015; Acc date: Apr 15, 2015; Pub date: Apr 17, 2015

Copyright: @ 2015 Roever L and Reis P. This is an open-access article distributed under the terms of the Creative Commons Attribution License, which permits unrestricted use, distribution, and reproduction in any medium, provided the original author and source are credited.

\section{Introduction}

Peripheral arterial disease (PAD) is common disease and associated with significant morbidity and mortality. PAD is caused due to fatty deposition on artery walls that leads to narrowing of the arteries and blockage in the main blood vessels of the lower limb, which may results in discomfort or pain in the legs during walk, as well as poor quality life and an increased risk of death because of heart and cerebrovascular diseases [1-6]. Risk factors for PAD are shown in Figure 1. The main aim of this review is to focus on the status and progress of screening for peripheral arterial disease.

A prevalence of $10 \%$ of people fewer than 70 years and $15 \%$ to $20 \%$ of people over 70 years, and an estimated prevalence of $13 \%$ in the age group over 50 years of age is estimated. Asymptomatic PAD may be responsible for up to $75 \%$ of cases and only $10 \%$ of sufferers have typical intermittent claudication. Many patients suffer from significant functional limitations, and the most severe cases are at risk of limb loss [7].

Physical examination shows decreased or absence of pulses in the legs and feet, and the color of the legs become pale when elevated above horizontal. The ratio of the leg to arm pressure is normally 1.0, but a ratio of less than 0.9 indicates that a significant blockage may be observed in leg artery. The severity of the reduction of ankle brachial index is classed as mild illness being 0.71 to 0.9 , moderate disease being from 0.5 to 0.7 , severe disease is less than 0.5 [7]. Two systematic reviews and meta-analysis, and contrasted the screening $\mathrm{ABI}$ and mortality and amputations results were included in a study. Screening for PAD has averaged $17 \%$ (range $1 \%-42 \%$ ) and was $1 \%$ to $4 \%$ in lowrisk populations. In patients with $\mathrm{PAD} \mathrm{ABI}$ was associated with an increased risk adjusted mortality from all causes (HR 2.99; 95\% confidence interval 2.16 to 4.12 ) and cardiovascular mortality (HR 2, $35,95 \%$ confidence interval 1.91 to 2.89 ). ABI screening was associated with prognosis and risk stratification for heart disease, although the data on benefits harms and cost-effectiveness of screening are limited [8].

Patients on hemodialysis $(\mathrm{n}=210)$ were examined using the anklebrachial index (ABI) and toe-brachial index (TBI). The prevalence of PAD was $38.1 \%$, and $42.5 \%$ were diagnosed with $\mathrm{TBI}<0.6$, although $\mathrm{ABI} \geq 0.9$. The prevalence of cerebrovascular disease was $36.3 \%$, coronary artery disease was $42.5 \%$ [9]. A study reported prospective cross-sectional study that included 162 patients who were evaluated and classified into three groups according to their ABI: normal ABI $(\mathrm{n}=104$, values between 1.00 and 1.40); Borderline PAD $(\mathrm{n}=23$, values between 0.91 and 1.00); and patients with PAD $(n=35, \leq 0.90)$. The presence of intermittent claudication (IC) was assessed using the Edinburgh Claudication Questionnaire and the level of physical activity was assessed by the short version of the International Physical Activity Questionnaire (IPAQ) and functional capacity was assessed by walking distance of 6 minutes (6MWT). The prevalence of PAD was $21.6 \%$. The $6 \mathrm{MWT}$ showed a strong correlation with the absence of IC $(\mathrm{r}=0.785 ; \mathrm{P}<0.001)$, moderate correlation with age $(\mathrm{r}=-0.347 ; \mathrm{p}$ $<0.001)$, and weak correlations with IPAQ score $(\mathrm{r}=0.164 ; \mathrm{P}=0.038)$ and $\mathrm{ABI}(\mathrm{r}=0.216, \mathrm{P}=0.006)$ [10]. According to another study 100 patients were selected with suspected obstructive sleep apnea (OSA) to $\mathrm{PAD}$, and polysomnography, ankle-brachial index (ABI), central pulse wave velocity, pulse wave index and duplex ultrasonography parameters were recorded for those patients. The prevalence of PAD was $88 \%, 68 \%$ had asymptomatic plaques and $20 \%$ were symptomatic Fontaine $\geq$ IIa. In OSA confirmed, prevalence rose to $98 \%$. Except for smoking, the distribution of established risk factors did not differ between OSA groups (patients with no, mild, intermediate and severe OSA). Board presence, Fontaine stage PAD and intermittent claudication showed significant gain with increasing AHI. Logistic regression showed that age $(\mathrm{OR}=1.199,95 \% \mathrm{CI}[1.066 ; 1.348])$ and AHI $(\mathrm{OR}=5.426,95 \% \mathrm{CI}[1.068,27.567]$ had the greatest influence on the presence of plaque [11]. Other study reported about two hundred forty-one Swiss multicenter cohort study (SSCS) of systemic lupus erythematosus (SLE) patients cross being evaluated for peripheral arterial disease (PAD). Patients with (SLE) were compared with a cohort of 193 patients with type 1 diabetes mellitus of the patients within the SSCS, $13.3 \%$ who had one or more vascular events: $1.2 \%$ PAD. In type-1 diabetes mellitus, $15 \%$ had vascular events: $5.6 \%$ PAD. Vascular events in patients with SLE were associated with age, duration of disease, dyslipidemia, and hypertension [12]. In a Korean study $(72.14 \pm 5.15$ years) PAD was detected in 79 subjects $(4.9 \%)$. Current smoking was significantly associated with PAD $(\mathrm{P}<0.001)$ [13]. A design was assessed $(n=135)$ in order to evaluate the prevalence of peripheral arterial disease (PAD) and its related risk factors in prediabetes patients. The prevalence of $\mathrm{PAD}$ in diabetes patients was higher than the normal group $(8.5 \%$ vs. $0.0 \%)(\mathrm{P}<0.05)$. The ABI in normal, prediabetes, and diabetes group was $(1.11 \pm 0.11),(1.09 \pm$ $0.12)$, and $(1.05 \pm 0.03)$ respectively $(P<0.1)$ [14]. In a meta-analysis $(n=43$ 919) showed that the ABI could reclassify 10-year risk for coronary artery disease (CAD) [15]. In a systematic review assesses the ability of non-invasive screening tests to detect PAD in patients with diabetes mellitus. Thirteen studies reporting sensitivity and specificity were only reliable in the identification or exclusion of PAD [16].

In a study with Familial hypercholesterolemia (FH), the authors assessed 202 patients ( $51 \pm 14$ years, $35 \%$ of men) with heterozygous FH (90.6\% with LDL receptor mutations), and total cholesterol levels of $342 \pm 86 \mathrm{mg} / \mathrm{dL}$. The prevalence of PAD was $28.2 \%$. An independent association between CVD and the diagnosis of PAD was observed ( $\mathrm{OR}=2.50 ; 95 \% \mathrm{CI}: 1.004-6.230 ; \mathrm{p}=0.049)$ [17]. In a prospective cross-sectional study $(n=329$, aged $>50$ years $)$ was conducted at a single emergency department were screened. The 
prevalence of PAD was 10.3\% (95\% CI7.5-14.1\%). The prevalence of symptomatic and asymptomatic PAD was $6.4 \%$ (95\% CI $4.2-9.6 \%)$ and $3.9 \%$ (95\% CI 2.3-6.7\%) [18]. Atherosclerosis diabetes is the major source of CVD in patients with diabetes mellitus types 1 and 2 (T1D and T2D). The diabetes is able to impair morphological and functional characteristics of the vascular walls and this condition plays as precursor of atherosclerotic disease. Family history of diabetes mellitus is related to increase in metabolic alterations predisposing to diabetes and increases cardiovascular risk profile of individuals. Although this is not supported by scientific evidences, many observational studies revealed its relationship [19-25].

Several methods [flow-mediated vasodilatation (FMD); anteroposterior abdominal aorta diameter (APAO); intima-media thickness of the common carotid artery (CCA-IMT); arterial stiffness; trying to assess their function, but have many limitations general characteristics of the population, and should be used according to gender and age [26]. Available evidence shows that PAD is common in patients with multiple cardiovascular risk factors and is associated with significant morbidity and mortality, but at the moment do not get benefits of your routine screening. Mortality and limb loss is greater in chronic asymptomatic $\mathrm{PAD}$, guidelines suggest that we should treat an asymptomatic $\mathrm{ABI} 0.7$ aggressively with smoking cessation, drugs, and lifestyle intervention.

\section{References}

1. Ridker PM, Cushman M, Stampfer MJ, Tracy RP, Hennekens CH (1998) Plasma concentration of C-reactive protein and risk of developing peripheral vascular disease. Circulation 97: 425-428.

2. Andras A, Ferket B (2014) Screening for peripheral arterial disease. Cochrane Database Syst Rev 4: CD010835.

3. Criqui MH, Langer RD, Fronek A, Feigelson HS, Klauber MR, et al. (1992) Mortality over a period of 10 years in patients with peripheral arterial disease. N Engl J Med 326: 381-386.

4. Vogt MT, Cauley JA, Newman AB, Kuller LH, Hulley SB (1993) Decreased ankle/arm blood pressure index and mortality in elderly women. JAMA 270: 465-469.

5. Ridker PM, Stampfer MJ, Rifai N (2001) Novel Risk Factors for Systemic Atherosclerosis: A Comparison of C-Reactive Protein, Fibrinogen, Homocysteine, Lipoprotein(a), and Standard Cholesterol Screening as Predictors of Peripheral Arterial Disease. JAMA 285: 2481-2485.

6. Hirsch AT, Criqui MH, Treat-Jacobson D, Regensteiner JG, Creager MA, et al. (2001) Peripheral arterial disease detection, awareness, and treatment in primary care. JAMA 286: 1317-1324.

7. Mohler ER 3rd (2012) Cardiology Patient Page. Screening for peripheral artery disease. Circulation 126: e111-112.

8. Alahdab F, Wang AT, Elraiyah TA, Malgor RD, Rizvi AZ, et al. (2015) A systematic review for the screening for peripheral arterial disease in asymptomatic patients. J Vasc Surg 61: 42S-53S.

9. Matsuzawa R, Aoyama N, Yoshida A (2015) Clinical Characteristics of Patients on Hemodialysis With Peripheral Arterial Disease. Angiology .

10. Nardi Gomes TJ, Martins de Albuquerque I, de Moraes Costa P, Cardoso DM, de Moraes Costa G, et al. (2015) Association between the anklebrachial index, intermittent claudication, and physical activity level: what is the influence on the functional capacity of patients with or at high risk of cardiovascular disease? Int J Gen Med 8: 55-62.
11. Schaefer CA, Adam L, Weisser-Thomas J, Pingel S, Vogel G, et al. (2015) High prevalence of peripheral arterial disease in patients with obstructive sleep apnoea. Clin Res Cardiol .

12. Koenig KF, Ribi C, Radosavac M, Zulewski H, Trendelenburg M; Swiss SLE cohort study (SSCS) (2015) Prevalence of vascular disease in systemic lupus erythematosus compared with type-1 diabetes mellitus: a cross-sectional study of two cohorts. Lupus 24: 58-65.

13. Cho WP, Park IS, Jeon YS, Kim JY, Kong T, et al. (2015) Vascular disease prevalence and risk factors in a screened Korean male population. Ann Vasc Surg 29: 215-221.

14. Faghihimani E, Darakhshandeh A, Feizi A, Amini M (2014) Evaluation of peripheral arterial disease in prediabetes. Int J Prev Med 5: 1099-1105.

15. Lin JS, Olson CM, Johnson ES, Whitlock EP (2013) The ankle-brachial index for peripheral artery disease screening and cardiovascular disease prediction among asymptomatic adults: a systematic evidence review for the U.S. Preventive Services Task Force. Annals of Internal Medicine 159: 333-341.

16. Ozdemir BA, Brownrigg JR, Jones KG, Thompson MM, Hinchliffe RJ (2013) Systematic review of screening investigations for peripheral arterial disease in patients with diabetes mellitus. Surgical Technology International 23: 51-58.

17. Pereira C, Miname M, Makdisse M, Kalil Filho R, Santos RD (2014) Association of peripheral arterial and cardiovascular diseases in familial hypercholesterolemia. Arq Bras Cardiol 103: 118-123.

18. Ng EL, Weiland TJ, Jelinek GA, Hadgkisst E, Wilson A (2014) Prevalence of and risk factors for peripheral arterial disease in older adults in an Australian emergency department. Vascular 22: 1-12.

19. Ciccone MM, Scicchitano P, Cameli M, Cecere A, Cortese F, et al. (2014) Endothelial Function in Pre-diabetes, Diabetes and Diabetic Cardiomyopathy: A Review. J Diabetes Metab 5: 364.

20. Balletshofer BM, Rittig K, Enderle MD, Volk A, Maerker E, et al. (2000) Endothelial dysfunction is detectable in young normotensive first-degree relatives of subjects with type 2 diabetes in association with insulin resistance. Circulation 101: 1780-1784.

21. Goldfine AB, Beckman JA, Betensky RA, Devlin H, Hurley S, et al. (2006) Family history of diabetes is a major determinant of endothelial function. J Am Coll Cardiol 47: 2456-2461.

22. Scuteri A, Tesauro M, Rizza S, Iantorno M, Federici M, et al. (2008) Endothelial function and arterial stiffness in normotensive normoglycemic forst-degree relatives of diabetic patients are independent of the metabolic syndrome. Nutr Metab Cardiovasc Dis 18: 349-456. 62 .

23. Hopkins KD, Lehmann ED, Jones RL, Turay RC, Gosling RG (1996) A family history of NIDDM is associated with decreased aortic distensibility in normal healthy young adult subjects. Diabetes Care 19: 501-503.

24. Pannacciulli N, De Pergola G, Ciccone M, Rizzon P, Giorgino F, et al. (2003) Effect of family history of type 2 diabetes on the intima-media thickness of the common carotid artery in normal-weight, overweight, and obese glucose-tolerant young adults. Diabetes Care 26: 1230-1234.

25. Anderwald C, Stadler M, Golay A, Krebs M, Petrie J, et al. (2010) Impact of family history on relations between insulin resistance, LDL cholesterol and carotid IMT in healthy adults. Heart 96: 1191-1200.

26. Ciccone MM, Bilianou E, Balbarini A, Gesualdo M, Ghiadoni L, et al. (2013) Task force on: 'Early markers of atherosclerosis: influence of age and sex'. J Cardiovasc Med (Hagerstown) 14: 757-766. 